Parenting a child with an ABI

The experiences of parenting a child with an acquired brain injury: A metasynthesis of the qualitative literature

Emma Tyerman $^{1}$, Fiona J R Eccles ${ }^{1}$, Victoria Gray ${ }^{2}$

${ }^{1}$ Division of Health Research, Faculty of Health and Medicine, Lancaster University, Lancaster, LA1 4YG, UK

${ }^{2}$ Psychological Services (Paediatrics), Alder Hey Children's NHS Foundation Trust, Liverpool, L12 2AP, UK 
Parenting a child with an ABI

\begin{abstract}
Objective: To systematically review and then synthesise the qualitative literature on the experience of parenting a child with an acquired brain injury (ABI).

Design: Systematic literature review and metasynthesis

Methods. A systematic search of the literature was conducted in four databases. Papers which met the inclusion criterion were assessed for quality using the Critical Skills Appraisal Programme (CASP) tool and then synthesised according to Noblit and Hare's (1988) guidelines for metaethnography.
\end{abstract}

Results. Of the 4855 papers retrieved, 17 met the inclusion criteria. Synthesis resulted in three themes: (1) Disconnection: Cut off from internal emotions and isolated from others; (2) Seeking understanding and support to manage in an insecure world; (3) New parent to a different child.

Conclusions. Having a child with an ABI leads to many challenges for parents. These include feeling insecure, isolated from others, and struggling to adapt to the different roles required to parent their different child. Clinical implications highlight the need for specialist support that is ongoing after discharge, including specialist knowledge and understanding of $\mathrm{ABI}$ and opportunities for peer support. 
Parenting a child with an ABI

\section{The experiences of parenting a child with an acquired brain injury: A metasynthesis of the qualitative literature}

\section{Introduction}

A significant proportion of those who experience acquired brain injury (ABI) are children. For example, within the UK, the Neurological Alliance [1] estimate that as many as 200,000 children have an ABI every year and $30 \%$ of attendances at accident and emergency departments for a head injury are children. ABI can have considerable consequences for the child, resulting in impairments in physical, cognitive, emotional and social functioning. For example, children with an ABI are more likely to exhibit behavioural problems [2-4] and are at increased risk of mental health difficulties such as depression, anxiety and obsessivecompulsive behaviours [3,5-9] They can also have problems with schoolwork, learning and friendships [3], probably due to impaired neurocognitive skills and reduced pragmatic skills and social problem soving [10]. Coupled with physical impairments these difficulties lead to restricted social participation [11]. ABI in younger children is also associated with worse long-term neurocognitive and psychosocial outcomes [12,13], perhaps due to the impact of the $\mathrm{ABI}$ on a child's developmental trajectory [12]. Hence ABI has significant implications for children both immediately but also for future development.

Parents of children with an $\mathrm{ABI}$ provide important support in managing the resulting difficulties [14]. Given the impact that ABI has on children, it is not surprising that it also affects parents' lives. This review focuses specifically on parents of younger offspring (under 18) as parental stress after paediatric traumatic brain injury (TBI; for example caused by an accident or a trauma) is reported to be greater when children are living at home than when grown up and living elsewhere [15]. Whilst moving out of home occurs at different ages, the transition to adulthood is often defined as age 18 in line with common cultural and 
legal norms. Consequently, this review will consider 'children' as up to and including age 18.

The quantitative literature suggests parents experience high levels of psychological distress [16] including anxiety and depression [17] and worsened physical health [18]. Shudy et al. [18] found that parents of children who are critically ill or injured experience a high level of stress, anguish, helplessness and aggravation due to role alteration and loss of control, creating a sense of helplessness. This pattern of high stress is similar for parents of children with TBI $[19,20]$ and persists over time [19]. Additionally parents of younger children can experience guilt for not protecting their child after a TBI [14].

This higher risk of psychological and physical health difficulties may in part be due to the high level of burden that parents experience [21,22] including relinquishing paid employment in order to care for the injured child as well as significant financial implications due to the cost of aids and hospital visits [19]. In addition parents own social activities are often reduced [19] which is likely to reduce emotional wellbeing [23,24]. Given that social relationships are helpful in managing difficult emotional experiences [25], parents are at risk of being left without key coping mechanisms at a time of high psychological distress.

Furthermore, experiencing high levels of distress may influence the ability to parent not only the child with ABI, but also any siblings. Parental psychological distress can have detrimental effects on child wellbeing generally as well as affecting parent-child relationships [26,27] and may lead to siblings experiencing behavioural and social difficulties and problems at school [28]. Thus it is important to understand the impact of having a child with an $\mathrm{ABI}$ on parents, not only to support their wellbeing but also to support the rehabilitation of the child with $\mathrm{ABI}$ and the psychological wellbeing of any other children in the immediate family. 
In summary, the quantitative literature shows that paediatric ABI has significant implications for parents, which has the potential to affect the psychological wellbeing and coping of all the family. It is therefore crucial that the experience of parents is understood in order to provide appropriate support. A body of qualitative research has explored parents' experience in depth but it is yet to be synthesised. Thus, this review will be completed in the form of a metasynthesis, which aims to enrich knowledge through synthesising the findings of research studies and producing additional interpretations [29], which together provides a fuller understanding of the phenomenon in question [30] and has the potential to generate helpful results for informing practice. It moves beyond describing qualitative research in a narrative review to the reinterpretation of data in published studies [31]. The aim of this metasynthesis is to increase understanding about the experiences of parents with a child with an ABI.

\section{Method}

\section{Design}

This review uses a metasynthesis approach to answer the research question: What are the experiences of parents of children with an $\mathrm{ABI}$ ? In order to find relevant papers the following eligibility criteria were developed and applied: (1) The paper described a research study using a qualitative approach; (2) The study focused on the experiences of parents of an individual with an ABI who was between 0 and 18 years of age ${ }^{1}$ at the time of injury; (3) The study was published in English due to financial restrictions for translation; (4) The study was published in a peer-reviewed journal, thus offering quality assurance.

Studies were excluded when: (1) The views of parents could not be separated from the views of others (for example, partners); (2) The information was a thesis, dissertation or a book due to access restrictions and lack of quality control via peer review; (3) Papers

\footnotetext{
${ }^{1}$ One paper included two grandparents [32]
} 
excluded children with $\mathrm{ABI}$ acquired at the time of birth because the parents had no experience of their child prior to injury; (4) The focus of the research was focused on the experience of an intervention or more specifically on the child (e.g. school re-integration or social participation) rather than the general phenomenon of being a parent to a child with an ABI; (5) The paper did not specify the age of participants or included participants over 18.

\section{Literature Search and Selection of Papers}

After consultation with specialist librarians, relevant literature was searched in three databases (PsycINFO, PubMed and Web of Science) on 17 March 2015 and an additional search was conducted in CINAHL in February 2017 but with an upper date limit of March 2015 in line with the other databases and thus the results represent the literature available up to that point. Search terms were identified by consulting relevant literature, specialists in neuropsychology and brain injury organisation websites (e.g. The Child Brain Injury Trust, The Children's Trust and The UK Acquired Brain Injury Forum).

Searching covered combinations and variations of the terms: "qualitative", "parents" and "acquired brain injury" (ABI). For example, to find qualitative papers, general terms such as qualitative or interview were utilised as well as specific approaches such as "narrative analysis" or "thematic analysis". To find papers related to parents, terms such as mother and father were included. For ABI terms included brain injury, stroke, brain haemorrhage and brain tumour. Table 1 gives a full list of free text search terms. As well as free text searching, medical subject headings in CINAHL, PubMed (MeSH headings) and PsycINFO (Thesaurus headings) were used (see Table 2). Limiters were placed in databases when this was available, "peer reviewed", "human subjects", or "English language" and all terms were 'exploded'. 
Parenting a child with an ABI

The following number of papers were identified in each database: CINHL 975, PsycINFO, 600; PubMed, 736; and Web of Science, 2544. Of a total of 4855 papers 1359 were duplicates across databases. Therefore, the titles of 3496 papers were reviewed against the eligibility criteria and 2789 were excluded. The abstracts of 707 papers were then examined against the criteria, resulting in the exclusion of a further 481 papers. The full texts of the remaining 226 were read and 15 papers identified that met the inclusion/exclusion criteria. Forward citation searching (searching for papers which cited the 15 papers) was performed via Google scholar which resulted in one further paper, as well as reference list searching which resulted in another paper that met the criteria. Thus, 17 papers were included in the review. The systematic process of identifying papers is summarised in Figure 1.

\section{INSERT FIGURE 1 ABOUT HERE}

\section{Characteristics of Included Studies}

The 17 studies were published between 1997 and 2015 from six countries: Australia $(n=4)$, Canada $(n=2)$, New Zealand $(n=1)$, UK $(n=4)$, Sweden $(n=3)$, USA $(n=2)$, and South Africa $(n=1)$. Three studies included a range of ABI aetiology [33-35], nine studies focused solely on TBI [32,36-43], four were focused on brain damage after a brain tumour [44-47], one study looked at hemiparesis specifically [48]. When papers met the inclusion criteria but not all findings were relevant to the research question the data of interest were extracted. For example, information regarding parents' reactions was extracted from studies about brain tumours, but themes about managing cancer treatment were excluded.

Thirteen studies included both mothers and fathers although two did not specify respective numbers and one just specified primary caregivers. Five studies looked only at mothers, one included two grandmothers [32]; given that grandmothers made up less than $7 \%$ of participants this study was included. The ages of children with ABI ranged from one 
month to 18 years; both genders were represented. Of those studies that reported time since injury, parents were interviewed up to 12 years post-injury but only one study included parents of children over 6 years post injury [40]. Two papers used the same data to answer two different research questions. Given that these had a very different focus and the second added additional data directly relevant to the research question, both were included but caution was taken to avoid undue influence of these participants on the metasynthesis [49].

In terms of data collection methods fifteen studies used interviews, one a focus group and two open-ended questions in a questionnaire. One of the papers that used interviews also used observations. All papers met the requirements for qualitative analysis as described by Sandelowski \& Barroso [50], i.e. the analysis produced interpreted themes. The analysis process varied in the level of interpretation and data transformation from content analysis to phenomenological analysis. The aims of the papers included general exploration of experience and emotional responses, informational and/or support needs, coping and adjustment, challenges, experiences of post-trauma and existential issues. Table 3 summarises the demographic and methodological details of the papers.

\section{INSERT TABLE 3 ABOUT HERE}

\section{Quality appraisal of papers}

Only peer reviewed studies were included to ensure they met a minimum quality. However, in addition, the Critical Appraisal Skills Programme (CASP) (Public Health Resource Unit, 2006) tool was used to assess quality (see Table 3 for CASP ratings). The CASP is a 10 point assessment criteria for qualitative research which includes two screening questions and a further eight questions. For example: 'Was the recruitment strategy appropriate for the aims of the research?'; and 'Have ethical issues been taken into 
consideration?' The papers were rated out of three for each criterion [51] giving a maximum score of 24 . The scores ranged from 17 to 24 .

\section{The synthesis process}

The analysis was completed systematically according to Noblit and Hare's [29] guidelines for a metaethnographic approach. Every effort was made to preserve the meanings and concepts of the original studies [52]. The papers were read repeatedly to gain familiarity with the main concepts and metaphors. A summary of key concepts in each paper was produced along with details of study design. The relationship between studies was then considered, looking for recurring common concepts. Following that, the studies were translated into one another by checking the concepts and themes in each paper against each other to develop further understanding. Britten et al. [31] suggest using first and second order constructs [53] as a way of distinguishing between everyday understandings that are participants' own reports (first-order) and constructs used by researchers that interpret the participant data (second-order). Finally, the translations were synthesised to create new understanding or reinterpretations (i.e. third-order constructs).

\section{Results}

Three themes emerged from the analysis: (1) Disconnection: Cut off from internal emotions and isolated from others; (2) Seeking understanding and support to manage in an insecure world; (3) New parent to a different child.

\section{Theme 1. Disconnection: Cut off from internal emotions and isolated from others}

Disconnection was evident both in the way many parents managed their intense emotions and in their relationships with partners and other children. Parents were also left feeling socially isolated as others were unable to understand their experience. 
Parents experienced intense and prolonged emotional reactions to their child's injury both immediately and years afterwards. This included depression [32], anxiety [33,38], stress $[39,42]$, guilt , anger $[40,48]$ and post-traumatic responses $[32,36]$ to such intensity that parents were left feeling emotionally exhausted. As one participant described: 'at times the hurt can come on so instantaneously it takes my breath away...I sometimes wonder when I'm not going to be sad' [48, p. 269]. These emotions were so intense that parents often ignored or avoided them in order to cope $[34,38-40,46]$. Other coping strategies included alcohol or drug use [35]. While such strategies were recognised as helpful in the short-term by some parents [34], as being disconnected from emotions meant they could manage the practical burden, they became detrimental in the long-term [34,39].

Although some studies found that the couple relationship was crucial to coping and adjustment, for others the theme of disconnection was observed within family relationships. As the needs of the child with an ABI were prioritised [45], parents struggled to invest in other family relationships [34,39]. As a result, some reported conflicts in their couple relationship such as disagreements over parenting and behaviour management given their child's changed needs $[40,45]$ or frustration at the lack of reciprocal support or appreciation [38,40]. This was exacerbated by different coping styles and reactions $[38,46,47]$.

Alongside the couple relationship, parents noticed the impact on their relationship with other children $[34,43,45,46]$. Some recognised that they were forced to neglect siblings' needs at times [46] despite recognising the siblings' distress [38,45,46]: 'Everything revolved around Josh [affected child] and Josh's wellbeing, so for Andy [sibling] he was starting to get a bit cheesed off with it' [47, p.746]. Even years post-injury, some parents felt they were more attentive to the child with $\mathrm{ABI}$ with a more intensive relationship, in contrast to emotional distance with the sibling $[45,46]$, despite efforts to counteract this $[38,45]$. 
In contrast other parents talked about feeling more connected and closer as a family unit $[34,36,42,45]$ because of their shared experience. For example, 'now it's more like us, it feels like we are more we' $[45, \mathrm{p} .375]$. However, this intra-familiar closeness contrasted with wider disconnection, as parents felt isolated and detached from society $[32,34,36,41,45]$. They felt misunderstood or judged by friends, family and professionals who could not truly understand what it was like to be a parent of a child with an ABI [32-34,38-40,46]. For example, one parent explained that: 'The pain and loss we experienced .... was made so much worse by having no one to talk to who we felt understood' [34, p. 287].

Some parents felt their child's difficulties were not recognised, understood or accepted by family and friends because they were not obvious [32,40-43]. Specific judgements about their child for example as manipulative or intentionally lazy or inappropriate advice based on a lack of understanding were particularly difficult [39-41]. The resultant barriers to their child's full social participation made parents feel disillusioned, frustrated, dismissed and sometimes avoided by others $[36,39,40]$.

This lack of recognition was not limited to the impact on the child with the ABI, as parents also experienced a lack of society's understanding of the impact of the ABI on all the family [32]. As a result, many parents felt they did not fit or belong with parents without a child with an ABI $[40,48]$. This meant that, although family and friends were important to help some parents cope $[36,39,41-43,47]$, for others, they were not able to provide the emotional support required as they could not connect with parents' experience. For this reason, some parents wanted to connect with others in similar situations $[34,39,48]$. For example, talking to other parents on the ward was helpful for some [38] although not for others [44] when survival and recovery was uncertain [32]. A lack of peer support opportunities within the community was noted $[39,40]$. 
Sharing the emotional burden with professionals offered an outlet $[37,38]$ and could be helpful in validating their experience [35-37]. However, some parents felt that professionals did not understand the social and cultural factors that affect families and their unique perspectives as they focused on a narrow medical approach rather than a holistic view [36,39]. This meant that professionals often missed what was important to families. Some parents sought counselling but opinions varied on its necessity and provision for this also varied [35].

\section{Theme 2. Seeking understanding to manage in an insecure world}

This theme reflects parents' need to obtain stability and security in an unstable and frightening situation. They sought to understand the situation and ensure their child received appropriate care.

Having a child with ABI resulted in fear and anxiety, initially due to uncertainty of the child's survival $[32,37,40,43]$. This was often followed by immense relief and feeling grateful on realising their child was alive, for example, on regaining consciousness $[33,35,40]$. However, this was often mixed with shock, confusion, and devastation on realising the extent of the ABI $[33-35,47]$ and not knowing how long the medical, cognitive and behavioural changes will continue [43]. This realisation happened over time as parents came to recognise the extent of and permanence of the ABI $[36,39,41]$. One parent described this process after their child's injury, 'everything was day to day,,,first, please God let him live...ok, he is going to live. Please God, don't let his brain damage be really bad..you get greedier and greedier... after that you just want a little bit more and a little bit more' [43, page 14]. Additionally parents expressed fears about the future for their child $[37,40,42,48]$ as to how the ABI would affect them (e.g. academically, [41,47]) and how society would accept them $[34,48]$. 
Parents' fears and uncertainty were experienced in the context of re-evaluating core values, views, priorities and fundamental assumptions about life $[33,38,42,45,46]$. Parents were confronted with ideas that life is unpredictable, unstable and dominated by fate or divine intervention and therefore experienced a loss of control or helplessness $[33,34,42,43,46]$. For example on parent stated, 'I think until something horrible happens to you, you kind of go through life thinking you have a bit of control and you think, if I am a good person and I try hard, and I work hard and I look after everybody and I try to be a good mother, things will go pretty well. But it doesn't work like that. Your stability goes out the window and what you've always based your life on you can't do it anymore because it's not there anymore' [33, p. 110].

Some parents attempted to manage their anxieties, uncertainties and changes in life perspective by considering themselves lucky that their child survived or wasn't as seriously affected compared to others $[40,43]$, by breaking down rehabilitation into small manageable milestones [34,38] or drawing strength from their spirituality [42]. Parents were also assisted in managing uncertainty by consistency in staff caring for their child $[32,34,44]$ which was also important in order to build relationships [35,38]. Trust and a feeling that staff cared were important elements of this for some parents $[32,34,39,44]$. This linked to parents' need to ensure that their child was receiving quality care. There seemed to be particular anxiety and criticism of care at times of increased uncertainty, such as transition from higher staffed intensive care wards to less intensive and difficult to access community services $[32,34,36,38,39]$.

As part of quality of care, many parents stressed the need for information and understanding [32,34,37-39,41,48]. This included information about ABI [37], medical procedures [37,54], prognosis [40], support available [34,37,40,47], behaviour management [40], as well as practical issues such as car parking [44]. However, parents in one study 
recognised a conflict between receiving and not receiving information, as both could cause exasperation and fear: 'You want all the information. But you don't want to know either' [44, p. 100]. Knowing typical emotional responses was also seen as helpful: 'well it's like, your feelings change all the time, from day to day, even from minute to minute at the beginning. It would have helped to know that what we felt was normal not madness' [34, p. 288]. These information needs were particularly important as many parents had little or no prior knowledge of ABI beyond television shows, which led to confusion [32]. When these information needs were met, many parents reported feeling relief and reassurance, and were less frustrated, fearful and apprehensive [35,44,47].

It was essential that information was accessible so parents could understand the language and have the opportunity to ask questions [32]. Unfortunately, many felt that the information provided was insufficient $[32,39,48]$ and some believed staff felt they would not understand or did not require the information [35]. Increasingly the parents in one study [39] described increasingly independent sources of information accessing books, the internet and talking to other parents.

Parents also stressed the importance of when and how the information was delivered as heightened emotions made it difficult for parents to absorb information [32,44,47]. Written information was helpful for this reason and telephone access for opportunities to ask questions once the information had been processed [40,47]. Many parents responded positively when information was given honestly, sensitively but frankly with empathy and compassion $[32,34,44]$.

Uncertainty about prognosis or when professionals were proved incorrect led to increased stress $[36,38,39]$. On the other hand, parents wanted acknowledgement of the uncertainty and respect for their need to maintain hope and positive thinking $[33,38,39,45]$ as 
Parenting a child with an ABI

noticing progress and maintaining hope was often important in holding things together [41]. Information tailored to parents' needs seemed important in facilitating understanding and reducing uncertainty.

\section{Theme 3. New parent to a different child}

Most of the papers discussed the need to adjust to being parents to a changed child. Along with grieving for the 'lost' child, parents tried to understand their new child and changed relationship.

A common finding was parents' pain and grief of the loss of the past child due to changes in cognitive ability, behaviour, personality and temperament. For example, 'This is not the same kid that went into the coma. Where is that...that used to be mine? He's not there, he's gone. And the bottom line is you almost treat it like a death. That child is no more... You have to go through a grieving process. You have to let go of what you had because he'd not the same child. His name is the same, he may look the same, he may not look the same. That's what really happens, is this huge sense of loss, just sometimes overwhelming sense of loss' [33, p. 109].

At first some parents aimed for maximum if not complete recovery [35]. However, many parents realised that the changes were most likely to be permanent [39] and that their child was profoundly different from the pre-injury child [33]. The pain of this realisation was only ever partially or temporarily relieved [34]. The impact of the brain injury often became apparent on arrival home [32]. At this point, parents had to begin to come to terms with a new and different child $[32,34,36]$ and adjust their expectations of their child's future $[39,48]$. A parent described realising that 'This isn't going to go away. This is going to be a lifetime. There is nothing that is going to fix this' [48, p. 267]. As a result, some parents felt robbed of the child's potential and idealised the pre-injury, 'perfect child' [34,39,40], making 
Parenting a child with an ABI

comparisons between pre and post injury [43]. However, other parents reported their child's recovery met their expectations which supported the grieving process [39].

Given the changes in the child, some parents reported the need to reconstruct another view of their child $[32,33]$. For example, they sought to understand their thoughts, feelings and reasons for behaviour, whether it could be attributed to the ABI, associated trauma, developmental stage or other life stresses $[40,41,43]$. In response parents altered their own behaviour and communication to try and compensate for their child's deficits [33]. Some felt that if they could not understand their child it was stressful and confusing [40] and greater emotional support was needed [32].

Many parents also reported a changed relationship with their child [33,36,38,45]. For some this meant a rupture and insecurity in their relationship, feeling like strangers to each other. However, others felt they had become closer to their child due to the time spent together and enhanced mutual appreciation. Parents had to adjust to a new way of relating to their child, for example, by finding behaviour management strategies for unpredictable behaviour $[40,42,46]$. Coping with behavioural changes was reported in one study [32] as the most concerning for parents in which they often felt unsupported. Parents also recognised that their own fatigue and emotional experiences (see theme 1) were making it harder to be consistent, provide structure and have time to teach their child new skills [40]. Parents reported a level of over-protectiveness, remaining alert to risks of further injury and guarding their children, particularly if told by professionals to be extra careful or watchful early in recovery $[32,38,41-43]$. Parents often felt uncertain about promoting independence versus protection from discomfort or more pain [32,40].

The new parent-child relationship involved many new roles while maintaining their parental role. Brown et al.'s [40] study identified a loss of their parenting role within the 
hospital environment. Being involved in care and decision-making reinforced the parent role and contributed to increasing confidence and ability to cope and reduced stress and anxiety $[32,35,37,38,44]$. However, some parents preferred not to be involved in specific care provision, for example bathing a child with intravenous therapy, or in specific decisionmaking, deferring to clinicians' expertise [32,35]

As the child progressed, parents took on increasing responsibility [32], sometimes in quasi-professionals roles $[39,45,54]$. This included acting as trainers to coach new skills and teachers to support with homework, taking on social work and advocacy roles by reorganising and networking services and managing legal proceedings and benefits $[34,39$ $42,48]$ and acting as medical assistants in observing symptoms and administering medication. They were also therapists, handling difficult questions and children's responses as well as interpreters for the wider family, friends and community. Some parents reported feeling inadequate in these unfamiliar roles due to uncertainty about techniques [45] and a fear of injuring the child [34]. The mothers in Shortman et al.'s study [47] described drawing on the responsibility of their maternal role to help them to cope.

Discharge was an important time in adapting to being a different parent but one that came with conflicting [38]:

You feel so alone and you feel, like I say, you're dealing with all this stuff that you've not got a clue really what you do, you know what I mean...it's like have you got a manual for this child? Because I don't know who he is and I'm trying to look after him and, as far as they was concerned, they'd sent him home...you just feel so alone and you're with this child that you don't really know what you're dealing with [32, p.308]. 
For some parents this meant giving up other important roles and activities that they previously undertook such as their employment, to become a full-time carer [33,40,42]. To help adopt these daunting roles, parents reported a number of helpful interventions. For example, trial periods at home before complete discharge and staff providing appropriate information, which decreased anxiety and increased confidence [32,35,38].

\section{Discussion}

This review highlights the challenging nature of having a child with ABI including social isolation, the insecurity of the situation and the challenges of adjusting to different roles required in parenting a changed child.

In the theme of disconnection: cut off from emotions and isolated from society, it was clear that parents had to find a way to manage their intense emotional experiences, with some disconnection in order to cope. This has some parallels with the emotional numbing that can occur after a trauma [55]. Use of distancing and avoidance as a defence against overwhelming emotional experiences has been found to be more likely when parents are experiencing high levels of stress [56].

Parents' social activity reduced and parents reported feeling isolated and different from others. This reduced social activity may be due to burden $[17,19]$, but the current findings also suggest that parents have difficulty connecting with others who do not understand and feel alone. While high levels of distress and trauma echo experiences of having a child with any chronic illness (for example, paediatric cancer [57]) the high levels of disconnection from others does seem particularly salient for these parents. This occurred, even when attending community groups for parents of children with a developmental disorder, which suggests there is something distinct about the ABI experience. 
The second theme of seeking understanding to manage in an insecure world, reflects findings from parents of children with chronic illness who similarly needed normality and certainty [58]. Information could go some way to provide certainty but, as with other chronic illness $[59,60]$, this was often felt to be lacking. Hawley et al. [3] found that over $70 \%$ of families with a child with a TBI had unmet information needs and some parents of more severely injured children were unable to take information in even when it was given. The findings in this metasynthesis highlight the need for information to be accessible in how and when delivered, as memory for medical information is generally poor [61]. When combining this generic retention problem with parents' extreme distress, it is not surprising that little information is absorbed. Furthermore, the current findings demonstrate how delivery interacts with parents' coping mechanisms, such as the need to maintain hope and how information assisted parents in anchoring themselves throughout the uncertainty.

The experiences described in the final theme of adjusting to being a parent to a different child and the loss of the child they knew, seemed more prominent for parents of children with ABI than other chronic illnesses (e.g. $[58,60])$ where onset of a condition is more gradual or indeed is present from birth, but is similar to the experience of family members of adult ABI survivors ([62]. The quantitative literature has highlighted the significant burden that parents experience in their caring role after paediatric ABI [19]. However, this review also highlights the wide range of these new roles and the different ways they contribute to burden. Many parents of other chronic conditions may identify with increased roles and adaptation to parenting styles and in some cases, a changed child in their emotional wellbeing and physical health [60]. However, after ABI there are additional cognitive and neuro-behavioural changes, associated relationship changes, and greater loss of the child's previous identity which add to the complexity of parenting a child with an ABI.

\section{Limitations}


Parenting a child with an ABI

There are a number of limitations to consider. First, although the results were drawn from participants from six countries, most of which were economically developed counties with arguably similar socio-cultural backgrounds. This may be in part due to the restrictive inclusion criteria of English language articles. In addition, (where reported) the ethnic origin was predominantly white. The results may not therefore apply to parents from different ethnic and/or cultural backgrounds. Second, the predominance of mothers might bias the results towards maternal experiences. This requires further research specifically looking at fathers' experiences, especially given some parents highlighted differences in coping styles between mothers and fathers.

Third, there was variety in the age range of children, time since injury and ABI aetiology. The age of children at ABI onset ranged from early infancy up to 18 years old. However, all of these parents are still parenting a child who, in the western cultural framework, is usually dependent on them, although in different ways. Time since injury also varied, though all except one study (of those which stated time since injury) were within 6 years of the injury and the one study outside this, the findings did not appear particularly different. The range of types of ABI has also indicated the similarity in parents' experiences, however half the studies focused on TBI, so may be biased towards this sub-group.

\section{Clinical Implications}

As in other paediatric illnesses (e.g. leukaemia; [63]) parents reported that professionals were often focused on physical health and neglected psychosocial implications. This suggests the professionals were working from a predominantly biomedical model and there might be benefit from greater application of biopsychosocial models (e.g. $[64,65])$ which adopt a wider systemic understanding of the family's coping to include interpersonal, in addition to intrapersonal, variables. 
As part of a greater psychosocial focus, this review emphasises the need to support parents through this traumatic and overwhelming experience, not only during acute care but through discharge and in the community. There is a clear need for professionals to recognise the emotional journey of parents, and for parents' grief to be acknowledged and validated to support this process and reduce feelings of guilt. There is also an argument for suitably trained professionals to provide emotional containment as some parents thought nurses were either too busy or not appropriately trained to respond to their needs. This could involve training nurses directly or other professionals groups such as clinical psychology providing direct support or supervision to ward staff.

This review suggests that interventions for parents might be beneficial. However, the choice of evidence-based interventions for parents caring for a child with a chronic illness is limited [66,67], particularly psychosocial interventions. On reviewing the chronic illness literature, Morawska, Calam \& Fraser [67] recommend that parenting interventions should include linking the illness with a child's behavioural and emotional adjustment, as well as with parenting strategies. They also emphasise the importance of addressing parents' information needs. Both of these recommendations are supported by the findings of this review. However, it is important to recognise that parents of children with ABI have distinct needs, as discussed previously, which may require specifically tailored interventions. The limited evidence base suggests such interventions have significant benefits for children and parents (for example [68,69]).

An important outcome from this metasynthesis was that not all parents had the same needs, for example regarding information content and timing of delivery and needs changed over time. Thus access to professionals that understand ABI and can tailor responses to individual family circumstances is important, especially in the community. It also suggests greater training in the wider professional community about the implications of ABI (for 
Parenting a child with an ABI

example, in schools - for further discussion see Anderssen et al. [70]). Parents also sought connection with other parents, which suggests there is an unmet need for specialist peer support groups which are accessible.

\section{Future research}

The studies in this metasynthesis only included papers where all children with an ABI were less than 18 years old. However, during the searching process, it was noted that a number of papers focused on children and young adults up to 35 years old (e.g. $[71,72])$. Given that western cultures are changing and young people live with parents for longer [73] it would be interesting to compare the findings with parents of young adults. Additionally, further research focusing on fathers' experiences is also required. Most importantly, this review has highlighted significant unmet need for parents, and provides further evidence of the need to explore effective ways of supporting these parents and evaluating existing interventions.

\section{Conclusion}

This review paper has synthesised the qualitative research on the experience of parents of children with ABI. The findings add to the quantitative literature by demonstrating why this experience is so challenging, as it requires significant adaptations to parents' relationships with themselves, their child, and their family and wider society. Parents' perspective that others did not understand their experience has the potential to leave parents feeling isolated and unsupported throughout managing this overwhelming experience. The findings therefore suggest that there is significant unmet need for support, and indicate a need for more research and evaluation of interventions for these parents.

\section{Acknowledgements}


Parenting a child with an ABI

Many thanks to Jenny Brine and Tanya Williamson, Specialist Librarians, Lancaster University for their help with the literature searches. Thank you also to Charlotte Ingham for her advice and support.

\section{Declarations of interest}

The authors report no conflicts of interest.

\section{References}

1. Neurological Alliance. 20033 June 2016. A brief review of the numbers of people in the UK with a neurological condition. Neurological Alliance 〈http://www.neural.org.uk/store/assets/files/20/original/NeuroNumbers.pdf $>$. Accessed 20163 June 2016.

2. Cole WR, Gerring JP, Gray RM, Vasa RA, Salorio CF, Grados M, Christensen JR, Slomine BS. Prevalence of aggressive behaviour after severe paediatric traumatic brain injury. Brain injury 2008;22(12):932.

3. Hawley C. Reported problems and their resolution following mild, moderate and severe traumatic brain injury amongst children and adolescents in the UK. Brain Inj. 2003;17(2):105-129.

4. Schwartz L, Taylor HG, Drotar D, Yeates KO, Wade SL, Stancin T. Long-Term Behavior Problems Following Pediatric Traumatic Brain Injury: Prevalence, Predictors, and Correlates. Journal of Pediatric Psychology 2003;28(4):251-263. 
5. Grados MA, Vasa R, Riddle MA, Slomine BS, Salorio C, Christensen J, Gerring J. New onset obsessive-compulsive symptoms in children and adolescents with severe traumatic brain injury. Depress. Anxiety 2008;25(5):398-407.

6. Green M, Foster MA, Morris M, Muir J, Morris RD. Parent assessment of psychological and behavioral functioning following pediatric acquired brain injury. Journal Of Pediatric Psychology 1998;23(5):289-299.

7. Max JE, Pardo D, Hanten G, Schachar RJ, Saunders AE, Ewing-Cobbs L, Chapman SB, Dennis M, Wilde EA, Bigler ED and others. Psychiatric Disorders in Children and Adolescents Six-to-Twelve Months After Mild Traumatic Brain Injury. Journal of Neuropsychiatry and Clinical Neurosciences 2013;25(4):272-282.

8. Max JE, Smith WL, Jr., Sato Y, Mattheis PJ, Castillo CS, Lindgren SD, Robin DA, Stierwalt JA. Traumatic brain injury in children and adolescents: psychiatric disorders in the first three months. J Am Acad Child Adolesc Psychiatry. Volume 36. United States1997. p 94-102.

9. Vasa R, Gerring JP, Grados M, Slomine B, Christensen, Jr., Rising W, Denckla MB, Riddle MA. Anxiety after severe pediatric closed head injury. Journal Of The American Academy Of Child And Adolescent Psychiatry 2002;41(2):148-156.

10. Yeates KO, Swift E, Taylor HG, Wade SL, Drotar D, Stancin T, Minich N. Short- and long- term social outcomes following pediatric traumatic brain injury. J Inter Neuropsych Soc 2004;10(3):412-426.

11. Bedell GM, Dumas HM. Social participation of children and youth with acquired brain injuries discharged from inpatient rehabilitation: a follow-up study. Brain Inj. Volume 18. England2004. p 65-82.

12. Donders J, Warschausky S. Neurobehavioral outcomes after early versus late childhood traumatic brain injury. J Head Trauma Rehabil 2007;22(5):296-302. 
13. Karver CL, Wade SL, Cassedy A, Taylor HG, Stancin T, Yeates KO, Walz NC. Age at injury and long-term behavior problems after traumatic brain injury in young children. Rehabil Psychol 2012;57(3):256-65.

14. Savage RC, DePompei R, Tyler J, Lash M. Paediatric traumatic brain injury: a review of pertinent issues. Pediatr Rehabil 2005;8(2):92-103.

15. Verhaeghe S, Defloor T, Grypdonck M. Stress and coping among families of patients with traumatic brain injury: a review of the literature. Journal of Clinical Nursing 2005;14(8):1004-1012.

16. Rivara JM, Fay GC, Jaffe KM, Polissar NL, Shurtleff HA, Martin KM. Predictors of family functioning one year following traumatic brain injury in children. - Abstract Europe PubMed Central. Archives of Physical Medicine and Rehabilitation 1992;73(10):899-910.

17. Wade SL, Taylor HG, Drotar D, Stancin T, Yeates KO. Family burden and adaptation during the initial year after traumatic brain injury in children. Pediatrics 1998;102(1 Pt 1):110-6.

18. Shudy M, de Almeida ML, Ly S, Landon C, Groft S, Jenkins TL, Nicholson CE. Impact of pediatric critical illness and injury on families: a systematic literature review. Pediatrics. Volume 118 Suppl 3. United States2006. p S203-18.

19. Hawley C, Ward AB, Magnay A, Long J. Parental stress and burden following traumatic brain injury amongst children and adolescents. Brain Inj. 2003;17(1):1-23.

20. Wade SL, Taylor HG, Drotar D, Stancin T, Yeates KO. Childhood traumatic brain injury: Initial impact on the family. Journal of Learning Disabilities 1996;29(6):652661. 
21. Rivara JM, Jaffe KM, Polissar NL, Fay GC, Liao S, Martin KM. Predictors of family functioning and change 3 years after traumatic brain injury in children. Arch Phys Med Rehabil. Volume 77. United States1996. p 754-64.

22. Wade SL, Taylor HG, Yeates KO, Drotar D, Stancin T, Minich NM, Schluchter M. Long-term parental and family adaptation following pediatric brain injury. J Pediatr Psychol 2006;31(10):1072-83.

23. Caunt BS, Franklin J, Brodaty NE, Brodaty H. Exploring the causes of subjective well-being: A content analysis of peoples' recipes for long-term happiness. Journal of Happiness Studies 2013;14(2):475-499.

24. Wang M, Wong MCS. Happiness and leisure across countries: Evidence from international survey data. Journal of Happiness Studies 2014;15(1):85-118.

25. Benn KM, McColl MA. Parental coping following childhood acquired brain injury. Brain Injury 2004;18(3):239-255.

26. Crnic KA, Gaze C, Hoffman C. Cumulative parenting stress across the preschool period: Relations to maternal parenting and child behaviour at age 5. Infant and Child Development 2005;14:117-132.

27. Oyserman D, Mowbray CT, Meares PA, Firminger KB. Parenting among mothers with a serious mental illness. Am J Orthopsychiatry 2000;70(3):296-315.

28. Fletcher JM, Ewing-Cobbs L, Miner ME, Levin HS, Eisenberg HM. Behavioral Changes After Closed Head Injury in Children. Journal of Consulting and Clinical Psychology 1990;58(1):93-98.

29. Noblit GW, Hare RD. Meta-ethnography: synthesizing qualitative studies. Newbury Park, CA and London: Sage; 1988. 
30. Thorne S, Jensen L, Kearney MH, Noblit G, Sandelowski M. Qualitive metasynthesis: reflections on methodological orientation and ideoloical agenda. Qualitative health Research 2004;14(10):1342-1365.

31. Britten N, Campbell R, Pope C, Donovan J, Morgan M, Pill R. Using meta ethnography to synthesise qualitative research: a worked example. J Health Serv Res Policy 2002;7(4):209-15.

32. Kirk S, Fallon D, Fraser C, Robinson G, Vassallo G. Supporting parents following childhood traumatic brain injury: A qualitative study to examine information and emotional support needs across key care transitions. Child: Care, Health and Development 2015;41(2):303-313.

33. Guerriere D, McKeever P. Mothering children who survive brain injuries: Playing the hand you're dealt. Journal of the Society of Pediatric Nurses 1997;2(3):105-115.

34. Menezes AM, Shinebourne EA. Severe brain injury after cardiac surgery in children: consequences for the family and the need for assistance. Heart 1998;80(3):286-291.

35. Ramritu PL, Croft G. Needs of parents of the child hospitalised with Acquired Brain Damage. International Journal of Nursing Studies 1999;36(3):209-216.

36. Clark A, Stedmon J, Margison S. An exploration of the experience of mothers whose children sustain traumatic brain injury (TBI) and their families. Clin Child Psychol Psychiatry 2008;13(4):565-83.

37. Falk AC, von Wendt L, Klange B. Informational needs in families after their child's mild head injury. Patient Education and Counseling 2008;70(2):251-255.

38. Robson T, Ziviani J, Spina S. Personal Experiences of Families of Children with a Traumatic Brain Injury in the Transition from Hospital to Home. Brain Impairment 2005;6(1):45-55. 
Parenting a child with an ABI

39. Roscigno CI, Swanson KM. Parents' Experiences Following Children's Moderate to Severe Traumatic Brain Injury: A Clash of Cultures. Qualitative Health Research 2011;21(10):1413-1426.

40. Brown FL, Whittingham K, Sofronoff K, Boyd RN. Parenting a child with a traumatic brain injury: Experiences of parents and health professionals. Brain Injury 2013;27(13-14):1570-1582.

41. Jones M, Hocking C, Wright -St Clair V. Parents caregiving for children after a traumatic brain injury: Structuring for security. New Zealand journal of occupational therapy 2010;57(1):4-13.

42. du Toit C, Coetzee Z, Beeton H. Mothers' experiences of caring for a child with severe brain injury in a disadvantaged community in the Cape Flats. South African Journal of Occupational Therapy 2013;43(2):17-22.

43. Bruce B, Chisholm J. Unintentional traumatic brain injury in children: the lived experience. Axone (Dartmouth, N.S.) 2001;23(1):12-17.

44. Jackson AC, Stewart H, O'Toole M, Tokatlian N, Enderby K, Miller J, Ashley D. Pediatric brain tumor patients: Their parents' perceptions of the hospital experience. Journal of Pediatric Oncology Nursing 2007;24(2):95-105.

45. Norberg AL, Steneby S. Experiences of parents of children surviving brain tumour: a happy ending and a rough beginning. European Journal of Cancer Care 2009;18(4):371-380.

46. Forinder U, Norberg AL. "Now we have to cope with the rest of our lives". Existential issues related to parenting a child surviving a brain tumour. Supportive Care in Cancer 2010;18(5):543-551. 
Parenting a child with an ABI

47. Shortman RI, Beringer A, Penn A, Malson H, Lowis SP, Sharples PM. The experience of mothers caring for a child with a brain tumour. Child: Care, Health and Development 2013;39(5):743-749.

48. Meehan DR. Mothering a 3- to 6-year-old child with hemiparesis. J Neurosci Nurs 2005;37(5):265-71.

49. Sandelowski M. Handbook for synthesizing qualitative research [electronic resource]. Barroso J, editor: New York, NY : Springer Pub. Co.; 2007.

50. Sandelowski M, Barroso J. Classifying the findings in qualitative studies. Qualitative Health Research 2015;13(7):905-923.

51. Duggleby W, Holtslander L, Kylma J, Duncan V, Hammond C, Williams A. Metasynthesis of the hope experience of family caregivers of persons with chronic illness. Qual Health Res 2010;20(2):148-58.

52. Silva FQB, Cruz SJO, Gouveia TB, Capretz LF. Using meta-thnography to synthesise research: A worked example of the relations between presonality on software team processes. Electrical and computer engineering publications. 2013;9(152-162).

53. Schutz A. Collected papers. The Hague : Nijhoff; 1964.

54. Clark A, Stedmon J, Margison S. An exploration of the experience of mothers whose children sustain traumatic brain injury (TBI) and their families. Clinical Child Psychology and Psychiatry 2008;13(4):565-583.

55. Ehlers A, Clark DM. A cognitive model of posttraumatic stress disorder. Behaviour Research And Therapy 2000;38(4):319-345.

56. Mednick L, Gargollo P, Oliva M, Grant R, Borer J. Stress and coping of parents of young children diagnosed with bladder exstrophy. J Urol 2009;181(3):1312-6; discussion 1317. 
Parenting a child with an ABI

57. Norberg AL, Lindblad F, Boman KK. Parental traumatic stress during and after paediatric cancer treatment. Acta Oncologica 2005;44(4):382-388.

58. Fisher HR. The needs of parents with chronically sick children: a literature review. Journal of Advanced Nursing 2001;36(4):600-607.

59. Hummelinck A, Pollock K. Parents' information needs about the treatment of their chronically ill child: A qualitative study. Patient Education and Counseling 2006;62(2):228-234.

60. Coffey JS. Parenting a child with chronic illness: a metasynthesis. Pediatric nursing 2006;32(1):51-59.

61. Kessels R. Patients' memory for medical information. J. R. Soc. Med. Volume 962003. p 219-222.

62. Petersen H, Sanders S. Caregiving and Traumatic Brain Injury: Coping with Grief and Loss. Health \& Social Work 2015;40(4):325-328.

63. Patistea E, Babatsikou F. Parents' perceptions of the information provided to them about their child's leukaemia. European Journal of Oncology Nursing 2003;7(3):172181.

64. Wallander JL, Varni JW, Babani L, Banis HT, Wilcox KT. Family resources as resistance factors for psychological maladjustment in chronically ill and handicapped children. Journal of Pediatric Psychology 1989;14(2):157.

65. Kazak AE. Pediatric Psychosocial Preventative Health Model (PPPHM): Research, Practice, and Collaboration in Pediatric Family Systems Medicine. Families, Systems, \& Health 2006;24(4):381-395.

66. Anderson T, Davis C. Evidence-Based Practice with Families of Chronically Ill Children: A Critical Literature Review. Journal of Evidence-Based Social Work 2011;8(4):416-425. 
67. Morawska A, Calam R, Fraser J. Parenting interventions for childhood chronic illness. Journal of Child Health Care 2015;19(1):5-17.

68. Brown FL, Whittingham K, Boyd RN, McKinlay L, Sofronoff K. Improving child and parenting outcomes following paediatric acquired brain injury: a randomised controlled trial of Stepping Stones Triple P plus Acceptance and Commitment Therapy. Journal of Child Psychology and Psychiatry 2014;55(10):1172-1183.

69. Wade SL, Wolfe C, Brown TM, Pestian JP. Putting the Pieces Together: Preliminary Efficacy of a Web-Based Family Intervention for Children with Traumatic Brain Injury. Journal of Pediatric Psychology 2005;30(5):437-442.

70. Andersson K, Bellon M, Walker R. Parents' experiences of their child's return to school following acquired brain injury (ABI): A systematic review of qualitative studies. Brain injury 2016;30(7):829-838.

71. Gebhardt MC, Grindel CG, McGehee LA, Testani-Dufour L. Caregiver and nurse hopes for recovery of patients with acquired brain injury. Rehabilitation Nursing 2011;36(1):3-12.

72. Jordan J, Linden MA. 'It's like a problem that doesn't exist': the emotional well-being of mothers caring for a child with brain injury. Brain injury 2013;27(9):1063-72.

73. Office for National Statistics. 2014 Families and Households: 2014.

<http://www.ons.gov.uk/peoplepopulationandcommunity/birthsdeathsandmarriages/fa milies/bulletins/familiesandhouseholds/2015-01-28>. 


\section{Table 1: Free search terms}

Qualitative OR "Grounded Theory" OR "Narrative Analysis" OR “Thematic Analysis" OR Experience OR "content analysis" OR ethnog* OR "Interpretative Phenomenological Analysis" OR "Discourse Analysis" OR "Framework Analysis" OR "Conversational analysis"

\section{AND}

“Acquired Brain Injury” OR "Brain Damage" OR "Traumatic Brain Injury" OR Meningitis OR Encephalitis OR "Hypoxic brain injury" OR "Anoxic Brain Injury" OR "Brain Injury" OR Stroke OR "Arteriovenous Malformation" OR Aneurysm OR "Brain Haemorrhage" OR "Cerebral Haemorrhage" OR Asphyxiation OR Suffocation OR "Brain Tumo*" OR "Cerebral Tumo*" OR "Brain Neoplasm” OR Neurosurgery OR "Head Injur*”

$$
\text { NOT }
$$

Alzheimer OR "Cerebral Palsy" OR Parkinson OR Dementia OR "Multiple Sclerosis" OR "Neurodegenerative Disorder" OR “Amyotrophic Lateral Sclerosis”

\section{AND}

Parent* OR Mother* OR Father* OR Mum OR Dad OR Caregiver* OR Family OR Families 
Parenting a child with an ABI

Table 2: Additional subject headings (thesaurus terms, MeSH headings)

Note: All terms were 'exploded' to include narrower terms

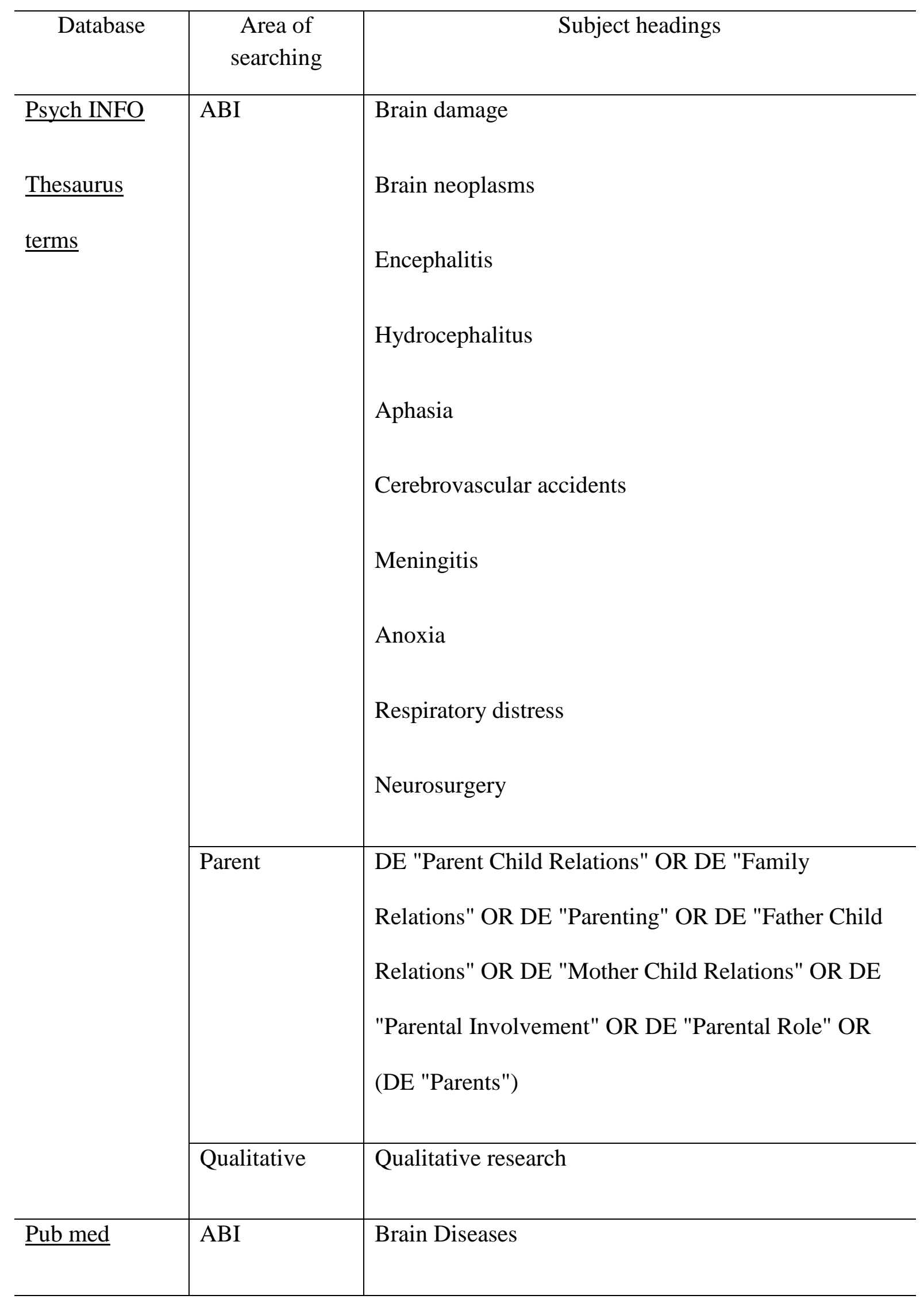




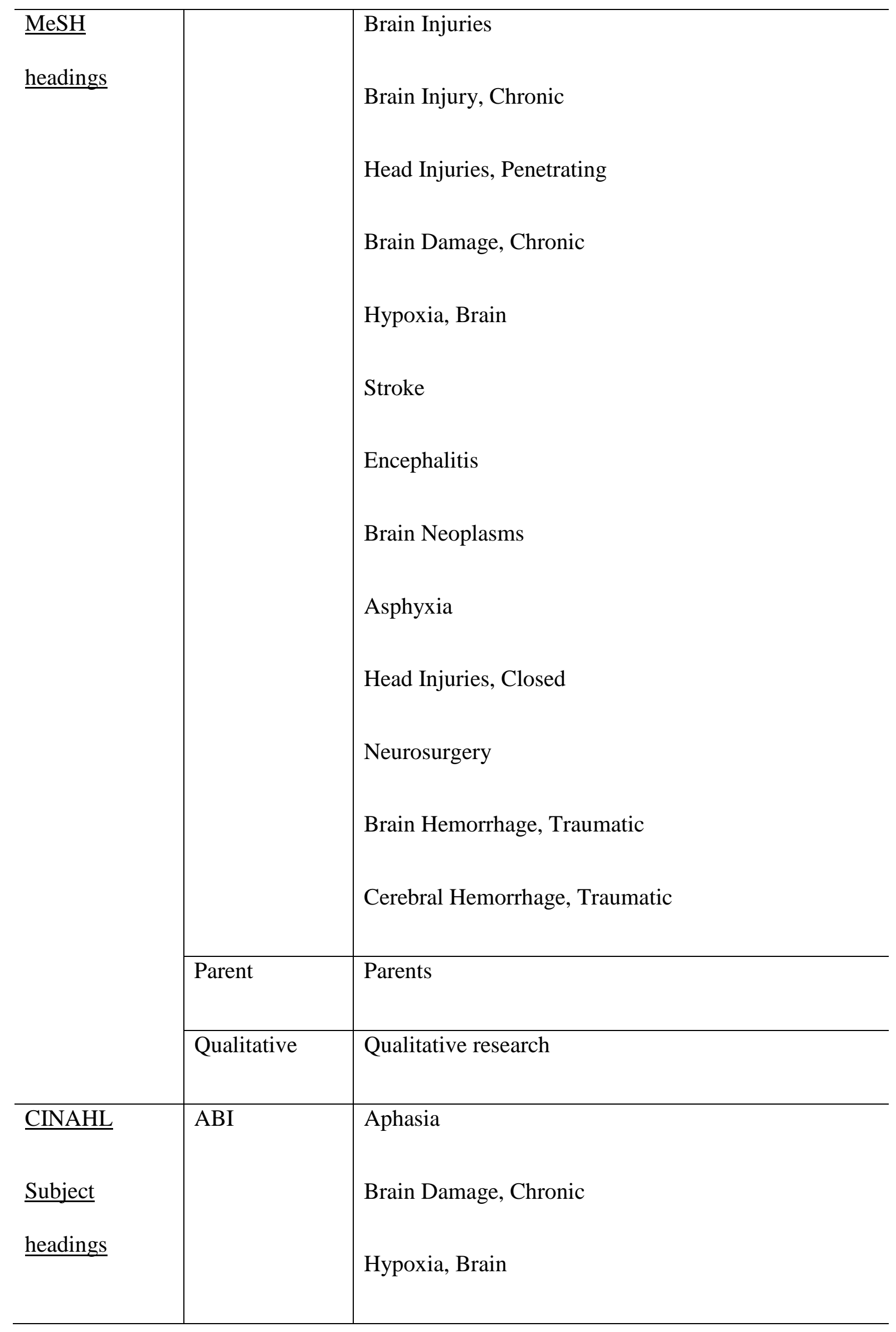




\begin{tabular}{l|l|l}
\hline & Brain Injuries \\
Brain Neoplasms \\
Encephalitis \\
& Head Injuries \\
& Hydrocephalus \\
& Neurosurgery \\
& Meningitis \\
& Anoxia \\
\hline Respiratory Distress Syndrome & Free text searching captured all results with subject \\
\hline & & \\
\hline
\end{tabular}


Parenting a child with an ABI

Table 3: Overview of included studies

\begin{tabular}{|c|c|c|c|c|c|c|c|c|}
\hline Author/ Year & Aim of study & Method of data & Method of & Current age / & ABI type & Time since & Mothers / & CASP \\
\hline Country & & collection & analysis & sex of child & & onset & Fathers & score \\
\hline
\end{tabular}

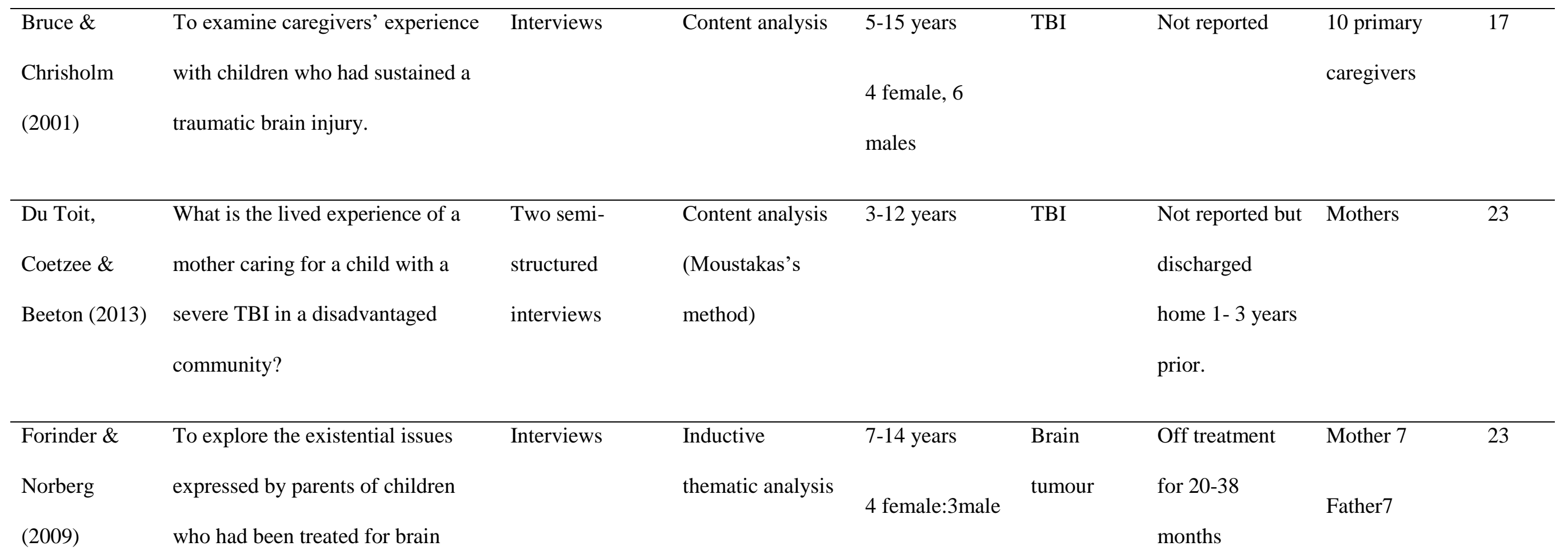

tumours. 
Parenting a child with an ABI

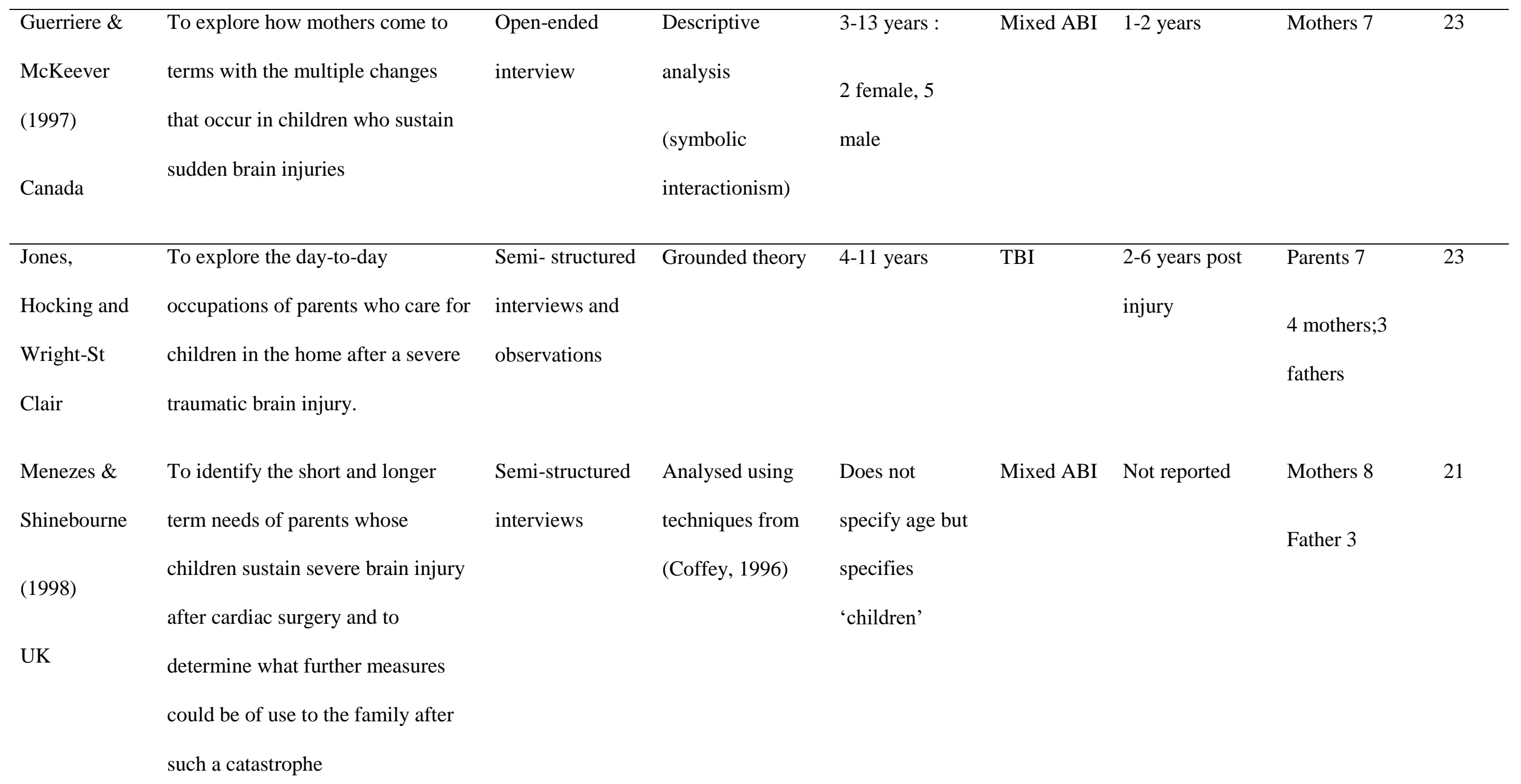


Parenting a child with an ABI

\begin{tabular}{|c|c|c|c|c|c|c|c|c|}
\hline Ramritu \& & To identify needs of parents of & Semi-structure & Content analysis & 6 wks-14 yrs & Mixed ABI & 1.5 years- 3.5 & 27mothers & 20 \\
\hline Croft (1999) & children with $\mathrm{ABD}$, admitted to a & interviews & & 5 female & & years & 7 fathers & \\
\hline Australia & $\begin{array}{l}\text { metropolitan tertiary referral } \\
\text { paediatric hospital throughout the }\end{array}$ & & & 23 male & & Mean $=2$ years & & \\
\hline & continuum of care & & & & & & & \\
\hline Robson, & To explore the experiences and & Semi-structured & Thematic content & $4.5-10.5 \mathrm{yrs}$ & TBI & Approx. & Parents: & 24 \\
\hline Ziviani \& & perceptions of parents of children & interview & analysis & & & 6months & 5 females & \\
\hline Spina (2005) & with TBIU in the transition from & & & & & & 1 male & \\
\hline Australia & hospital to home & & & & & & & \\
\hline Meehan & To describe the experience of & Unstructured & Colaizzi’s & 3 to $6 y r s$ & Hemi- & Not specified & Five & 21 \\
\hline$(2005)$ & mothering 3 to 6 -year-old children & interviews & method- & & paresis & & mothers & \\
\hline
\end{tabular}


Parenting a child with an ABI

\begin{tabular}{|c|c|c|c|c|c|c|c|c|}
\hline Jackson et al. & To explore coping adaptation and & 2 open ended & Thematic analysis & Under 18 yrs & Brain & 4 time points & 53 parents & 21 \\
\hline (2007) & adjustment in families of a child & questions in & (Creswell, 1994) & & tumour & (dx to $2 \mathrm{yrs}$ post) & Genders & \\
\hline Australia & with a brain tumour. & questionnaire & & & & & unknown & \\
\hline Clark, & To explore the nature and quality of & Semi-structured & Interpretive & $11-16$ years & TBI: 7 & $2-6$ years & Mothers 10 & 24 \\
\hline Stedmon \& & family members emotional & interview & phenomenology & 10 male & Moderate / & & & \\
\hline Margison & responses and any change in the & & cal analysis & & severe 7 & & & \\
\hline (2008) & family and clinical relevance of & & & & Unclear 3 & & & \\
\hline UK & different psychological theories. & & & & & & & \\
\hline Roscigno \& & To describe the common & Two semi- & Descriptive & $8-20$ years & TBI: & 4 months - & 34 mothers & 23 \\
\hline Swanson & experiences of English speaking & structured & phenomenology & Gender un & Moderate & 3 years. & 8 fathers & \\
\hline$(2011)$ & parents of children with TBI. & interviews & cal framework & specified & 13. Severe & & & \\
\hline
\end{tabular}

USA 
Parenting a child with an ABI

\begin{tabular}{|c|c|c|c|c|c|c|c|c|}
\hline Falk, von & To characterise the informational & Questionnaire & Content analysis & 1mth-15 yrs & Mild head & 3 months after & 57 parents & 22 \\
\hline Wendt \& & needs of parents \& compare these & with one open & (Krippendorff, & 24 female & injury & the injury & Does not & \\
\hline Klange & to previously determined needs of & ended question & 2012; Weber, & & & & specify & \\
\hline (2008) & $\begin{array}{l}\text { parents whose children have } \\
\text { suffered more serious injury }\end{array}$ & & 1990) & 33 male & & & gender & \\
\hline \multicolumn{9}{|l|}{ Sweden } \\
\hline Norberg \& & To capture a panorama of parents & In-depth & Inductive & $7-14$ years & Brain & Off treatment & 7 mothers & 23 \\
\hline Steneby & experiences of post-traumatic & interviews & thematic analysis & & tumour & for $20-38$ & 7 fathers & \\
\hline (2009) & influence & & & & & months & & \\
\hline \multicolumn{9}{|l|}{ Sweden } \\
\hline Brown, & To add to the current understanding & Small focus & Transcribed > & $5-17$ years & TBI & $2-12$ years & Mothers 7 & 23 \\
\hline Whittingham, & by further exploring the & group & inductive & 2 female, 6 & moderate, & & (mother 1 ) & \\
\hline Sofronoff \& & experiences, challenges and needs & discussions of & thematic analysis & male & 4 , severe 4 & & Fathers / & \\
\hline Boyd (2013) & of parents of children with $\mathrm{ABI}$. & structured & & & & & step-father & \\
\hline Australia. & & questions. & & & & & 2 & \\
\hline
\end{tabular}


Parenting a child with an ABI

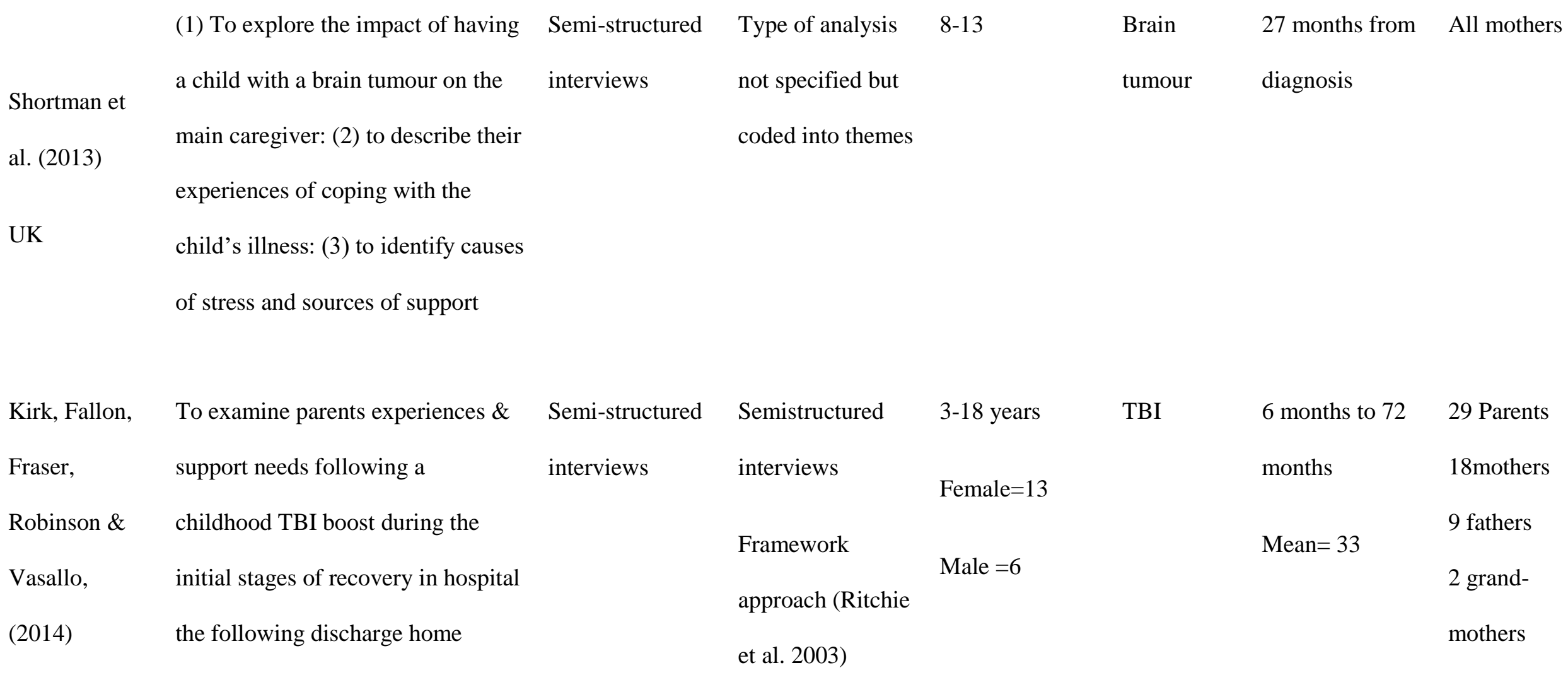

UK 
Parenting a child with an ABI

Identified articles from search of electronic databases (CINAHL, Psych

INFO, Pub Med, Web of Science):

Total $=4855$

Duplicates found $=1359$

Papers excluded $=2789$

Articles reviewed on title

$=3496$

Additional articles that met criteria $=2$

(1 from forward citations searching and 1 from reference list searching)

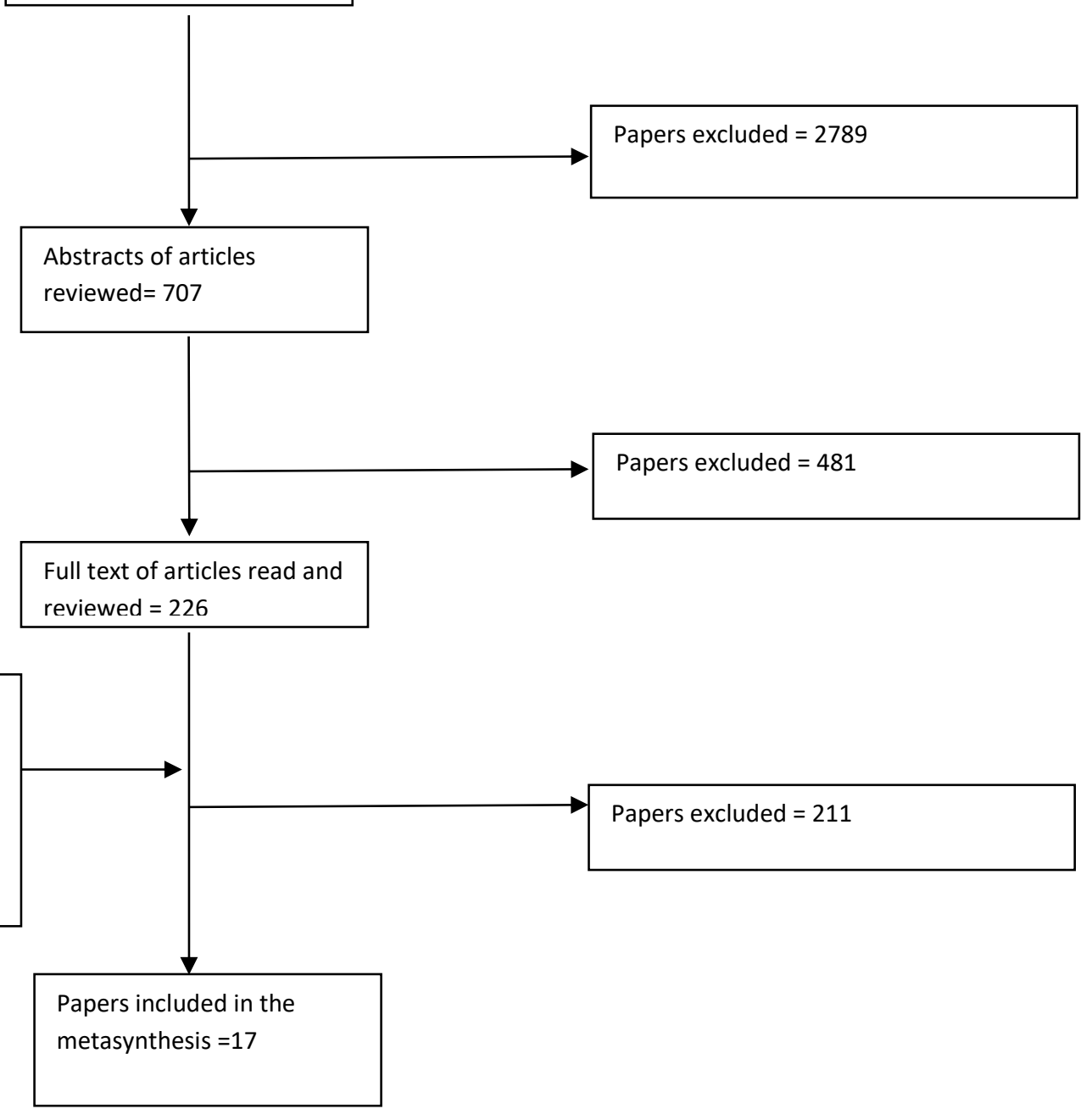

